\title{
1. Studying trust as process within and between organizations
}

\author{
Søren Jagd and Lars Fuglsang
}

\section{INTRODUCTION}

The goal of this book is to bring forward new knowledge about trust and processes in an organizational context. We argue that there is a need, on the one hand, to explore how trust is formed through processes of social interactions in which social actors observe, reflect upon and make sense of trust behaviour and its meaning in an organizational and social context. On the other hand, we need to explore how trust forms a constitutive element in social processes more generally in organizations. The goal of this book is to explore these two aspects of the intertwining of trust and social processes within and between organizations.

Trust understood as 'confident positive expectations regarding another's conduct' (Lewicki et al., 1998, p. 439) is today often seen as a precondition for social and economic development. Further, trust is sometimes regarded as a phenomenon that can be found - but not created (for example Sabel, 1993). Research shows, however, that trust can be influenced and manipulated through both social institutions and social interaction. Institutional arrangements, such as regulations and norms, can enable trust-relations at the interpersonal and inter-organizational level (Bachmann, 2001; Bachmann and Inkpen, 2011). Interaction with third parties (Burt and Knez, 1995; Ferrin et al., 2006; Lau and Liden, 2008) or management systems (Mayer and Davis, 1999) can also facilitate trust. Finally, trust relies on social processes of sensemaking that allow actors to explore and make sense of the foundation of trust at the interpersonal and institutional level (Fuglsang and Jagd, 2015).

Together, these different insights show that while the basic propensity to trust may be difficult to impact, because it is formed in early childhood (Erikson, 1965), anchored in culture (Saunders et al., 2010) and probably relatively stable over time (Fleeson and Leicht, 2006), the 
specific trust-relations among social groups are dependent on microprocesses of negotiation, interpretation and sensemaking (Wright and Ehnert, 2010). Furthermore, these micro-processes, where actors come to reinterpret their mutual relations, can be framed by structures of management, interaction and governance (Gausdal, 2012) and trust processes may also contribute to the reproduction and change of institutions (Fuglsang and Jagd, 2015). Following this, the purpose of this book is to explore how trust is framed by and is framing processes and structures of management, interaction and governance in various contexts. The book will build on a series of qualitative case studies that illustrate the characteristics of trust-building processes. The focus of trust as process has been neglected in trust research for many years, but is beginning to receive more attention in recent years (Lyon et al., 2015). The book thus seeks to contribute to the process view of trust by providing case-analysis of trust-building processes.

Since Zand's (1972) model of the dynamics of trust in the early 1970s, a considerable body of literature on trust building, trust maintenance and trust repair in organizations has accumulated. There is now a widespread consensus that trust is a multifaceted process that develops over time, rather than consisting of a limited set of discrete events. Thus, there is a need for process views of trust in order to better analyse how trust formation takes place and how different trust processes affect the reproduction of organizations. The concept of 'process', which has lately been emphasized in research, is, however, not a very clear term, and it is difficult to define in a unitary way (see Chia and Langley, 2004; Hernes, 2008; Langley, 2007). Rather than discussing process theory in a general sense, the focus of this book is to distinguish and explore processes and practices of social interaction important to trust formation.

Although trust is commonly seen as being built and reproduced through dyadic interactions, taking an explicit ontological assumption of trust as process is still not usual in trust research. Nevertheless, notable exceptions may be found. An early contributor to conceptualizing trust in a process perspective may be the German sociologist Georg Simmel who, as demonstrated by Guido Möllering (2001, 2006), conceptualized trust as a process of interpretation leading to expectation supported by a 'leap of faith'. More recently, Fernando Flores and Robert C. Solomon (1998) argued that trust is a dynamic aspect of human interaction and human relationships:

Trust is a dynamic aspect of human relationships. It is an ongoing process that must be initiated, maintained, sometimes restored and continuously authenticated. Trust is not a social substance or a mysterious entity; trust is a social 
practice, defined by choices. It is always relational: A trusts $\mathrm{B}$ (to do C, D, E). We can say that A is 'trusting', but by that we mean that he or she has a disposition to readily trust people. Indeed, the very word 'trust' is misleading, in so far as it seems to point to an entity, a thing, some social 'stuff'. Although we will continue to use the word, it might better be thought of as 'trusting', an activity, a decision, a transitive verb, not a noun. (Flores and Solomon, 1998, p. 206)

Following Dmitry Khodyakov (2007), a definition of trust as process should explain 'how all three temporal properties (the past, present, and future) influence the creation, development, and maintenance of trust' (Khodyakov, 2007, p. 125). Thus, process studies can be thought of as both focusing a sequence of events (creation, development and maintenance) and as an ontology of temporal properties that influence these events. Yet little, if any, research exists that is based on such a theoretical perspective.

Though empirical studies applying an explicit process perspective still may be scarce, notable exceptions are found. Maguire et al. (2001) analyse trust development between pharmaceutical companies and HIV/ AIDS community organizations in Canada, focusing on the dynamics of identification-based trust. The study shows that discursive activity generating new identities is crucial for generating and maintaining identification-based trust. Adobar (2005) studied trust creation as a process of sensemaking in which small cues are enlarged through the incremental accumulation of evidence. Thus, trust building in partnerships may be a sort of self-fulfilling prophecy in which initial expectations positively impact behaviour and trust building. Recently, Nikolova et al. (2015) studied how clients and consultants actively create and maintain trusting relations. Trust creation is conceptualized as 'a sociocognitive-emotional process' consisting of three interrelated practices: (1) signalling ability and integrity; (2) defining, negotiating and aligning to clients' expectations to demonstrate benevolence; and (3) demonstrating likability and personal fit (Nikolova et al., 2015, pp. 241-3).

The need for an explicit process approach may be revealed by the inherent tension in much trust research between a general agreement that trust is somehow created and reproduced through interactive processes, but nevertheless returning to an ontological assumption of trust as something that can be studied as if it is relatively stable, often applying different variations of survey study approaches. If trust is created and reproduced through interactive processes we need to apply methods that are able to capture the processes involved in the creation and reproduction of trust, hence we cannot rely on surveys alone. Lewicki et al. (2006, p. 992) point out that although we have learned a great deal from 
"snapshot" studies that measure trust at a single point in time and test its relationship with hypothesized variables of interest, they provide limited insight into the dynamic nature of the growth and decline of trust over time within interpersonal relationships.'

Therefore, according to Guido Möllering, trust should be studied and conceptualized as 'a continuous process of forming and reforming the attitudes static surveys have measured so far and, crucially, as part of larger social processes' (Möllering, 2013, p. 285).

Huang and Wilkinson (2013) also point out that because the majority of studies on trust have been largely a-historical, a-processual and a-contextual, 'the specific mechanisms and processes through which trust develops and changes - the dynamics of trust - are less well understood' (Huang and Wilkinson, 2013, p. 463). In order to address this gap Huang and Wilkinson propose to study how trust develops and evolves over time based on the interaction of various psychological, social and economic mechanisms. Jarratt and Ceric (2015) further stress the limits of much process theory that fails to acknowledge properly the continuing evolution of an individual's dispositional trust, the imperfect perceptions of dynamics of cognitive trust, and the fragility of trust. To address these limitations of existing process theories of trust, Jarratt and Ceric propose to draw on insights from complexity theory which may help capture the interacting, self-organizing and emergent properties of trust.

Following these perspectives, in this book we intend to contribute to the understanding of how such 'trusting' is initiated, maintained, restored, continuously authenticated, and repaired as an integral part of social practices.

\section{WHAT IS A PROCESS VIEW?}

Process studies address questions about 'how and why things emerge, develop, grow, or terminate over time, as distinct from variance approaches dealing with co-variation among dependent and independent variables' (Langley et al., 2013). Langley and Tsoukas (2010), in their introduction to process organization studies, point to three conceptual dualities, which in different ways inspire studies of processes in organizations: process vs. substance metaphysics; process vs. variance theorizing; and narrative vs. logico-scientific thinking (see Table 1.1).

Process studies of organizations are inspired by process metaphysics (Whitehead, 1929) stating that processes, rather than substances, are the basic form of the universe. Events, states, or entities are unpacked by 
revealing the complex relations made among them that together reproduce patterns and structures over time (Hernes, 2014, p. x). Becoming, change, flux and disruption are main themes of a process worldview. Process metaphysics regards change as constitutive of the world. Process theory demonstrates how patterns and structures are created and stabilized by processes and events rather than explaining how structures create events.

Table 1.1 Features of process and variance approaches

Process approaches Variance approaches

\section{Process metaphysics}

Processes, rather than substances, are the basic form of the world.

Events, states or entities are unpacked by revealing the complex activities and transactions that take place and contribute to their constitution.

\section{Process theorizing}

Process theories provide explanations in terms of patterns between events, activities and choices over time.

\section{Narrative thinking}

Incorporates temporal linkages between experienced events over time. It is a form of knowing used to give meaning to particular events drawing on culturally embedded narrative structures.

\section{Substance metaphysics}

Processes are explained in terms of substances: processes contingently happen to substances, but substances are essentially unchanging in character.

\section{Variance theorizing \\ Variance theories provide explanations of phenomena in terms of relationships among dependent and independent variables.}

\section{Logico-scientific thinking} In logico-scientific (or paradigmatic) knowing generalizations are made about causal influences among variables.

Source: Adapted from Langley and Tsoukas (2010).

The distinction between 'process' and 'variance' theories was introduced by Mohr (1982). While process theories provide explanations in terms of patterns made between events, activities and choices over time, variance theories provide explanations in terms of relationships among dependent and independent variables. Process models deal with events and their 
interconnecting, rather than variables, and, in process models, time ordering among the antecedents is crucial for the outcome.

The distinction between narrative vs. logico-scientific thinking is another way to describe two different forms of knowing. While logicoscientific knowing provides propositions or rules that connect categories of behaviour to categories of actors and situations, narrative knowing places actors and situations in a temporal, contextualized form, thus capturing nuances dropped in the abstraction process that is characteristic of paradigmatic knowing (Langley and Tsoukas, 2010). Narrative knowing is a form of knowing used to give meaning to particular events drawing on culturally embedded narrative structures.

A distinction has further been made between 'weak' and 'strong' process approaches according to the degree to which a strong process ontology has been applied (Bakken and Hernes, 2006). Weak process approaches build on phase models describing stages of development. Stronger process approaches propose the generative mechanisms active in producing these temporal sequences (Welch and Paavilainen-Mäntymäki, 2014). The strongest process approaches are based on the assumption that process is constitutive of the world - and hence that the task of research is to demonstrate the processual nature of things (Hernes, 2014).

Welch and Paavilainen-Mäntymäki (2014), calling for revitalizing process studies of the internationalizations process of firms, have analyzed how a process dimension has been downplayed in recent studies of internationalization. This analysis points towards crucial aspects of the research process important for revitalizing process studies more generally.

First, it is important to pose the initial research question explicitly as a process related question. While we may pose questions about the building, maintenance and the destruction of trust (weak process perspective), we may also ask questions about how particular forms of trust are important for the constitution of particular forms of relations among organizational actors (stronger process perspective). Asking how trust is involved in the production and reproduction of organizations may show how different forms of trust are important for different forms of organizing. Finally, we may aim to demonstrate the processual nature of trust as such (strongest process perspective).

Second, in deciding on the nature of the data set it is important to collect process data. This point may seem obvious but collecting process data is time-consuming and may be difficult to obtain so we may be inclined to collect data that are more readily available, such as interview data, that only to a limited degree highlight how trust is important for organizational processes. 
Third, when we have access to process data we should analyze the data processually by identifying generative mechanisms, studying processes instead of antecedents or outcomes, studying a chain of events rather than a single event, focusing on temporality in the analysis, and offering process-based models in the conclusion.

\section{HOW TO STUDY TRUST AS PROCESS}

What does it mean to take an explicit process approach to the study of trust? In the following we explore different suggestions regarding applying a process perspective to organizations more generally and to the phenomena of trust more specifically.

The concept of 'process' has been lately emphasized in organizational research by Tor Hernes (2008), who highlighted two basic assumptions in process perspectives on organizations (Hernes, 2008, p. 128). The first is the ontological assumption that the world exists as flows in which entities are in a state of becoming rather than as a final state of being.

As discussed above, although trust is commonly seen as being created and reproduced through interaction processes, taking the ontological assumption of trust as process is still rare in trust research (but see Dibben, 2000, 2004 for an exception). In this book we attempt to show how trust is created and reproduced through the formation of social interaction processes which are repeated over time. Methodologically we primarily apply qualitative studies of processes involved in the creation and reproduction of trust.

The second assumption in process approaches to organizations, according to Hernes (2008), relates to epistemology assuming that 'actors intervene in the world of flows equipped with their understandings of how it works, and equipped with models of how to bring some order, either by continuing doing what they are doing already or by attempting to stabilize the worlds that surround them into some intended pattern' (Hernes, 2008).

This assumption points to the importance of actors' understanding of how the interaction in which they are involved actually works. Learning from and reflecting upon past experiences of social interaction then becomes of utmost importance for actors' interventions in social interaction and understanding of how to proceed in their social practices.

Möllering (2013) distinguishes, as summarized in Table 1.2, between five process views on trusting, highlighting different mechanisms in trusting: (1) continuing; (2) processing; (3) learning; (4) becoming; and (5) constituting. They can be placed, he argues, on a continuum from 
moderate to pronounced views on trusting, from trust as processing to trust as a process in itself (Möllering, 2013).

\section{Table 1.2 Five process views on trusting}

\begin{tabular}{|c|c|c|}
\hline Trusting as & $\begin{array}{l}\text { Example research } \\
\text { questions }\end{array}$ & Research emphasis \\
\hline Continuing & $\begin{array}{l}\text { How does trust change } \\
\text { over time? }\end{array}$ & Longitudinal \\
\hline Processing & $\begin{array}{l}\text { How do trustors and } \\
\text { trustees generate and } \\
\text { 'process' information } \\
\text { in order to produce the } \\
\text { outcome of trust? }\end{array}$ & Interpretation \\
\hline Learning & $\begin{array}{l}\text { How does trust change } \\
\text { as a result of learning? }\end{array}$ & Building-up \\
\hline Becoming & $\begin{array}{l}\text { How is trust involved in } \\
\text { producing knowledge, } \\
\text { social identities and } \\
\text { relationships? }\end{array}$ & Identity \\
\hline Constituting & $\begin{array}{l}\text { How is trust involved in } \\
\text { the production of social } \\
\text { structures? }\end{array}$ & Practices \\
\hline
\end{tabular}

Source: Adapted from Möllering (2013).

We also suggest, however, that we may distinguish process views by exploring processes of social interaction in a more concrete and empirical way. For example, some processes may be characterized by individual interventions and others by collective interventions. Thus, this book has a more empirical focus, trying to explore and theorize through case studies how processes of formation of social interaction can affect trust formation and how trust can affect individual identities and the formation of social interaction.

Even if we have to assume the social world to be flat (Friedman, 2005) it may be helpful analytically to distinguish between different processes involving trust. These different processes are not in opposition but are intertwined in several ways. First, trust may be studied as mental processes. Researchers have investigated how trust produces a certain state of mind cognitively and affectively (for example Hardin, 1993; 
McAllister, 1995). A key question is how 'individual actors develop and hold positive expectations in the face of uncertainty and vulnerability towards others' (Möllering, 2013).

Second, trust may be studied as social processes. Here we distinguish between three intertwined social processes: dyadic processes involving two actors, group/organizational processes, and societal processes. We can thus distinguish different ways in which actors observe, reflect upon and make sense of trust behaviour of others as a basis for social intervention. This can involve an individual's relation to others (an individual person observing and reflecting upon others' trust behaviour), and various forms of collective reflections on trust behaviour. These different forms of trust processes may be understood as simultaneously available or overlapping rather than as separate forms, that is, as dimensions in a social learning process (see Figure 1.1).

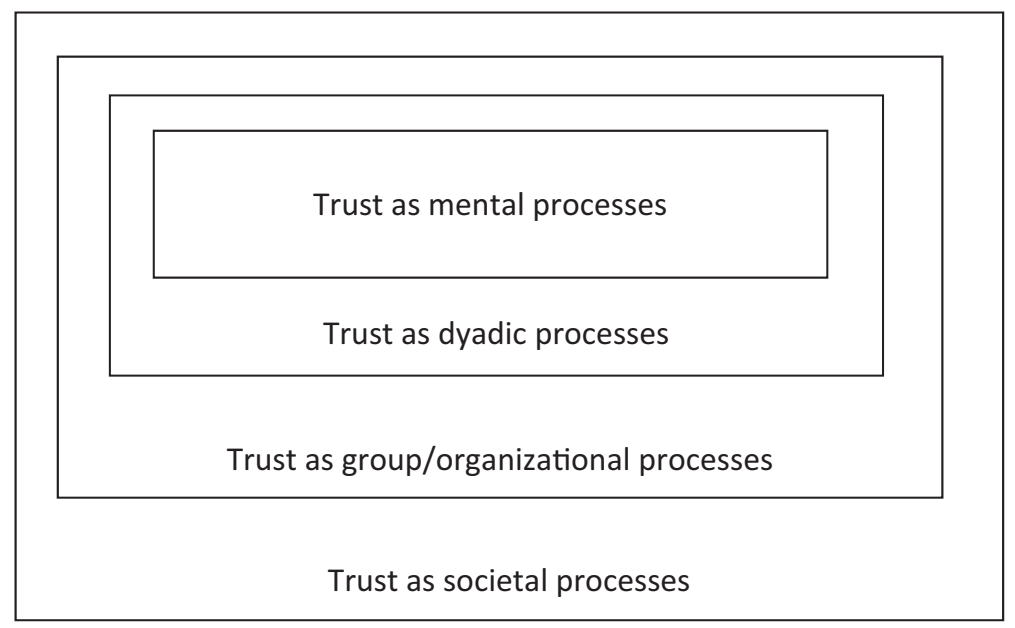

\section{Figure 1.1 Trust as a multilevel phenomenon}

- Individual trust processes: in this case trust/distrust is produced by individual actors observing and reflecting individually upon other relevant social actors' trust behaviour and its meaning. This may for example be a new employee in a company, who observes the behaviour of colleagues. From social interactions with these oldtimers the employees must reflect on the meaning of the observed processes. Another example may be an employee observing a manager or a manager observing groups of employees - thus trying to figure out what the meanings and expectations in this social situation are. 
- Dyadic trust processes: in this case, two people together observe and reflect upon the meaning of the trusting behaviour of others or themselves. It could be two colleagues in a company that are colleagues or friends. It could also be two managers who together are seeking to understand what kind of trusting behaviour is relevant in a giving context, thus adapting and applying the relevant trust repertoire themselves to the given situation.

- Group trust processes: group learning is when a group of people reflect mutually upon and discuss their own trust behaviour in relation to another group or a new situation. This may be both a formal group, such as a committee, or it may be more spontaneously gathered groups such as people exchanging views during a lunch break. Groups may be temporary or more permanent.

Furthermore, we can distinguish different distances to the observed reality that the social interaction process relates to. We use here Khodyakov's distinction between thick, thin and institutional trust (Khodyakov, 2007). The trustors may thus observe the trusting behaviours of others with whom there is a thick, thin or institutional relationship.

- Thick interpersonal trust: these are the strong ties between people who know each other well, like in close business relationships, family-based firms or groups of employees that know each other well. This may also be across firms in groups of facilitated networks where people build strong relationship to each other. In thick trust the basis for learning and exploring a common meaning of trust is strong due to repeated actions and the mutual moral obligations that can be present in such a community.

- Thin interpersonal trust: thin trust concerns the weaker ties between people who do not know each other well and will not come to know each other well. These relationships can also be learned by individual, dyadic, group or network-based learning processes. For example, two people can exchange experiences about the trust behaviour of a more distant third party and learn to adapt to this. This could be consumers in relation to providers of goods and services with whom they have no direct day-to-day contact.

- Institutional trust: this concerns trust based on institutions. Here too the social learning of trust can be seen as common exploration of meaning in social interaction. Confronted with, for example, the police, a citizen must make up his or her mind whether the police 
are to be trusted and what behaviour to adapt vis-à-vis the police. There can be many differences and nuances in institutional trust across situations, authorities, countries and cultures that require continuous social learning.

We can conclude that trust can be seen as a process of formation of social interaction where social actors observe, reflect upon, make sense of and explore a common meaning of trust and intervene in social interaction. The social actors may be in a thick, thin or institutional relationship with each other. Social interaction may take place along different dimensions: individually, in dyadic relations, in groups or in networks. By looking more closely into these relationships the book contributes to: (1) clarifying what a process view may mean in trust research; (2) understanding how social interaction processes affects trust; and (3) theorizing trust as dependent on the exploration of a common meaning.

\section{AN OVERVIEW OF THE BOOK}

The book is structured in four parts: the first part focuses on how trust differs in various situations. The second part focuses on trust as action exploring the actor- and sensemaking-dimension in organizational trust by studying how actors are bound to make sense of the institutional and organizational environment in which they operate and how it impacts trust. The third part focuses on trust and time, exploring how trust becomes stabilized over time through ongoing efforts to frame trustrelations and create imprints of trust as well as distrust. The final part provides analyses of the complex interplay of different types of trust/ distrust processes evolving over time within large organizations and between actors and organizations.

In the first part, the focus is on variations of trust in different situations. It is widely accepted that trust is a multiplex, dynamic phenomenon. Nevertheless, we still need to understand how the notions of trust and trusting actually differ in various situations. From a process perspective, we may ask what actually causes processes of trusting or of distrusting to develop in different ways, producing very different outcomes. This part contributes to trust as process research by exploring how various perspectives on variations of trust and distrust may help us understand different dynamics of trust processes.

In Chapter 2, Johansen, Espedal, Grønhaug and Selart argue that different situations call for different forms of adaptations that correspond to different forms of trust. Three different forms of trust are discussed: 
trust as decision, trust as performance and trust as an uncontrollable force. In the chapter, the authors show how these three types of trust differ with respect to assumptions about trust, trustworthiness and agency as well as with respect to accompanying emotions. The chapter conclude by outlining a tentative process-model of trust and indicating questions for further research.

In Chapter 3, Frederiksen investigates the relationship between trust in institutions, trust in people and the interaction between these forms of trust from a phenomenological perspective. The analysis takes its point of departure in Luhmann's analysis of risk and danger as residing in different experiences of temporality. Building from the phenomenology of Løgstrup, the chapter argues that the experience of confidence belongs in the temporality of continuity - of stable contexts and dangers. Trust is in fact not a reaction to risk but a different phenomenological mode. Trust resides in a temporality of process and an unguarded attitude, whereas risk resides in a temporality of events, calculation and potential regrets. Institutions interact with trust in providing familiar handles on situations to determine when risk or trust seem appropriate. Frederiksen introduces the notions of trust compartments and risk compartments in order to describe the way people map social topographies of trust/process and risk/event from institutional embedding.

In Chapter 4, Allwood, Berbyuk Lindström and Johansson explore the enactment of accountability as a critical aspect of establishing and maintaining trust relationships. The chapter contributes to an understanding of trust as a dynamic relational process that varies with circumstances. Based on an analysis of a number of physician-patient consultations in a Swedish hospital, they show how the consultations lead to increased or decreased trust, and in some situations have no apparent effect. The consultations, and the accounts given in them, can possibly lead to trust if they correspond to the uncertainty or the needs the other party expresses, assuming willingness to collaborate and cooperate.

In the second part, the focus is on understanding trust as action and how institutional and organizational structures can enable and inspire trust-relations, yet the organizational context may often appear unstable, unfamiliar to the actors and ambiguous (Fuglsang and Jagd, 2015). People are bound to make sense of the institutional and organizational environment in which they operate, and how it affects trust. This part contributes to trust as process research by paying attention to the actorand sensemaking-dimension in organizational trust, a perspective on institutional and organizational trust which appears to be underexplored in the literature. 
In Chapter 5, Näslund argues that trust creation can be conceptualized as a process of interactional sensemaking between trustor and trustee. Empirically, the study is based on an interview study of Swedish management consultants and clients and the client-consultant relationship as it evolves during sales meetings and collaboration. It is shown that the trust-creating process relies on improvisational skills which require experience and it is facilitated by shared frames of reference, such as would be provided by a common habitus. The chapter demonstrates that by conceptualizing trust creation as an interactional process of sensemaking, enacted through improvisation, we can further our understanding of trust creation as process.

In Chapter 6, Mogensen analyses how two actors retrospectively made sense of the war and peace agreement in Aceh, Indonesia. With the purpose of adding to theories about the impact of macro-events on trusting at the micro level, this explorative study provides an analysis of seven episodes of trust which contributes to a sensemaking perspective on trust. They demonstrate that - in retrospect - trust and risk assessment has been an ongoing intersubjective process in which trust repertoires have been continually adapted, first throughout decades of war, and later during peace negotiations and decommission. The analysis of the seven episodes also gives indications of what bases of trust people rely on in high-risk situations. For example, there are indications that perceptions of the divine can provide an alternative framework for sensemaking during times when institutions cannot support trust.

In Chapter 7, Gausdal explores trust-building processes in networks, with particular emphasis on the link between practical intervention methods and trust-building processes. Based on a comparative case study with longitudinal data of three Norwegian regional networks, the chapter investigates dialogue-based methods that facilitate social learning of trust in networks. It argues that the participants must meet face-to-face to develop joint terms and understanding. Further, the participants should work together with reflection tasks organized in small, temporary, inter-organizational groups with time pressure, requiring all participants to be active by sharing, reflecting on, and having dialogues about experiences and challenges within the firms. The main contribution of the chapter is to increase the understanding of trust-building processes in networks as social learning processes at a practical micro level.

In Chapter 8, Malkamäki, Ikonen and Savolainen aim at improving the understanding of the trust-building process by an in-depth study of the implementation of a new management system (MS). The case study focuses on trust-building between two functional organizational units within a Finnish chain of hypermarkets. The study is based on qualitative 
interview-data gathered from actors at different organization levels. The chapter shows that the management system may play an important role in trust-building between organizational units by enabling a common understanding of a common goal, supporting a clarification of roles and responsibilities, and procedures for the basis for efficient cooperation.

In the third part, the focus is on how trust and distrust become stabilized over time through ongoing efforts to frame trust-relations and create imprints of trust as well as distrust. Trust in an inter-organizational context or in project teams relies partly on interpersonal relations. However, the relation between interpersonal trust and inter-organizational relationships or teamwork is an issue of great interest for trust studies. The chapters in this section contribute to this research from a process perspective and provide an analysis of trust and distrust as something that evolves over time.

In Chapter 9, Swärd explores the concept of imprinting in an interorganizational context. Imprints are conditions or perceptions created during short, critical periods and remain stable over time. Despite the numerous studies on imprinting, the relation between imprinting and trust processes in inter-organizational relations remains to be further analysed. Insight about the imprinting process is gained from an explorative longitudinal study of two partners on a construction project that occurred in 2009-2013. The chapter offers insight into how we can understand imprinting in relation to trust - specifically, how trust imprints are created, how imprints persist, and why imprints change.

In Chapter 10, Perry applies the process perspective to a case study of the trust and distrust building between a group of young men with minority ethnic backgrounds, a team of youth workers, a job consultant and a police officer. The chapter deals with the frames used by the young men to organize the public sector employees, either as trusting or distrusting, along with some of the cultural tools used to construct these frames. The key question that the chapter deals with is: how can trust and distrust be understood as cultural frames? The case study reveals that both trust and distrust can be influenced and manipulated through social interaction over time and through the subsequent sensemaking processes in the context. The chapter contributes towards understanding the microprocesses at play in trust and distrust-building processes.

In Chapter 11, Hansen, Bosse and Rasmussen focus on how expectations are negotiated and changed. Symbolic interactionism is applied in the analysis of the ongoing and challenging relationship between an investment manager and an entrepreneurial team. The ethnographic narrative offers a rich description of how expectations are negotiated and changed as a part of trusting interactions. It provides the readers with 
insights into the relationship between expectations and trusting and how the developed framework based on symbolic interactions constitutes a productive framework for studying trusting in a process perspective.

In Chapter 12, Savolainen and Ikonen explore the development of trust as process in a team context, focusing on how the process of trust building emerges. The empirical study is conducted in two teams: a sports team and multi-professional team. By applying Kozlowski et al.'s theorizing of emergence (Kozlowski and Chao, 2012; Kozlowski et al., 2013), the purpose of this study is to produce empirically richer knowledge of the process of trust development by illuminating the way in which the process emerges in the team context.

The final part provides analyses of the complex interplay of different types of trust/distrust processes evolving over time within large organizations and between actors and organizations. The chapters in this section contribute to this research from a process perspective and provide analyses of complex interplay of different types of trust/distrust processes evolving over time.

In Chapter 13, Neisig applies Möllering's (2013) five process views of trusting: continuing, processing, learning, becoming, and constituting to an empirical study of a change process in a municipality in Denmark. By investigating a Danish free municipality trial in a job centre transforming from a New Public Management paradigm towards a New Public Governance paradigm, the chapter explores how the different stages of trusting in Möllering's framework may build on each other and how obstacles in trusting at lower stages might impose great difficulties in reaching good results in trusting at higher stages. These five process views are seen as layered or at least partly layered. Neisig finds that this layered understanding may explain major obstacles in change processes that involve changing trust relationships.

In Chapter 14, Vallentin and Thygesen explore a trust-based public sector reform from the point of view of the trust-control nexus. It is argued that trust reform in the public sector may be considered as a process that involves an interweaving of trusting and controlling mindsets and practices. Thus, the case is made for a complementary (as opposed to substitutive) view of trust and control. Vallentin and Thygesen argue that the role of trust in this context may be understood in lieu of the prevalence and interactions of different governance paradigms: the classical model of public administration, new public management (NPM) and new public governance (NPG). The empirical study focuses on reform efforts within home care in the Municipality of Copenhagen. Home care has been singled out as a low-skilled service area besieged by management control, documentation requirements and monitoring. However, 
instead of aiming to show how trust-based reform - in accordance with the ostensible benefits of trust promoted in the trust literature - can serve to liberate home care employees, the main concern is to showcase the intricate reconfiguration of social relationships that such reform gives rise to, in order to contribute to a more nuanced understanding of the trust-control nexus.

In Chapter 15 Elllingsen explores the relationship between trust and social change. The empirical example is a study of how changes in economic organization at the macro level - deregulation - can transform the trust relationship at the micro level - here between a savings bank and customers. The chapter presents a process view on trust based on interactionism and classic sociology combined with a grounded theory methodology. The perspective is that trust is a dynamic and multilevel process of social construction. Development and maintenance of trust is a dynamic process of sensemaking and social construction based on interplay between pre-contractual, relational and structural social bases. Mutual understanding is the trigger of the leap of faith, from doubt into trusting. The chapter analyses how deregulation transforms the social bases for trust between the savings bank and the customer and how trust is lost and then restored. The main finding is that social changes at the macro level influence trust relationships at the micro level and that social change is about changes in the social bases for trust.

\section{REFERENCES}

Adobar, H. 2005. 'Trust as sensemaking: The microdynamics of trust in interfirm alliances'. Journal of Business Research 58(3): 330-37.

Bachmann, R. 2001. 'Trust, power and control in trans-organizational relations'. Organization Studies 22(2): 337-65.

Bachmann, Reinhard and Andrew C. Inkpen. 2011. 'Understanding institutionalbased trust building processes in inter-organizational relationships'. Organization Studies 32(2): 281-301.

Bakken, Tore and Tor Hernes. 2006. 'Organizing is both a verb and a noun: Weick meets Whitehead'. Organization Studies 27(11): 1599-616.

Burt, Ronald S. and Marc Knez. 1995. 'Kinds of third-party effects on trust'. Rationality and Society 7(3): 255-92.

Chia, Robert and Ann Langley. 2004. 'The first Organization Studies summer workshop: Theorizing process in organizational research (call for papers)'. Organization Studies 25(8): 1486.

Dibben, Mark R. 2000. Exploring Interpersonal Trust in the Entrepreneurial Venture. Basingstoke: Macmillan. 
Dibben, Mark R. 2004. 'Exploring the processual nature of trust and cooperation in organisations: A Whiteheadian analysis'. Philosophy of Management 4(1): 25-39.

Erikson, E.H. 1965. Childhood and Society. Harmondsworth: Penguin.

Ferrin, Donald L., Kurt T. Dirks and Pri P. Shah. 2006. 'Direct and indirect effects of third-party relationships on interpersonal trust'. Journal of Applied Psychology 91(4): 870-83.

Fleeson, William and Christine Leicht. 2006. 'On delineating and integrating the study of variability and stability in personality psychology: Interpersonal trust as illustration'. Journal of Research in Personality 40: 5-20.

Flores, F. and R.C. Solomon. 1998. 'Creating trust'. Business Ethics Quarterly 8: 205-32.

Friedman, Thomas. 2005. The World is Flat. London: Allen Lane.

Fuglsang, Lars and Søren Jagd. 2015. 'Making sense of institutional trust in organizations: Bridging institutional context and trust'. Organization 22(1): 23-39.

Gausdal, A.H. 2012. 'Trust-building processes in the context of networks'. Journal of Trust Research 2(1): 7-30.

Hardin, R. 1993. 'The street level epistemology of trust'. Politics and Society 21: 505-31.

Hernes, Tor. 2008. Understanding Organization as Process: Theory for a Tangled World. Abingdon: Routledge.

Hernes, Tor. 2014. A Process Theory of Organization. Oxford: Oxford University Press.

Huang, Yimin and Ian F. Wilkinson. 2013. 'The dynamics and evolution of trust in business relationships'. Industrial Marketing Management 43: 455-65.

Jarratt, Denise and Arnela Ceric. 2015. 'The complexity of trust in business collaborations'. Australian Marketing Journal 23: 2-12.

Khodyakov, D. 2007. 'Trust as a process: A three-dimensional approach'. Sociology 41(1): 115-32.

Kozlowski, Steve W.J. and Georgia T. Chao. 2012. 'The dynamics of emergence: Cognition and cohesion in work teams'. Managerial and Decision Economics 33: $335-54$.

Kozlowski, Steve W.J., Georgia T. Chao, James A. Grand, Michael T. Braun and Goran Kuljanin. 2013. 'Advancing multilevel research design: Capturing the dynamics of emergence'. Organizational Research Methods 16(4): 581-615.

Langley, Ann. 2007. 'Process thinking in strategic organization'. Strategic Organization 5(3): 271-82.

Langley, Ann and Haridimos Tsoukas. 2010. 'Introducing "Perspectives on Process Organization Studies”". In Tor Hernes and Sally Maitlis (eds) Process, Sensemaking, \& Organizing. Oxford: Oxford University Press, pp. 1-26.

Langley, Ann, Clive Smallman, Haridimos Tsoukas and Andrew H. Van de Ven. 2013. 'Process studies of change in organization and management: Unveiling temporality, activity, and flow'. Academy of Management Journal 56(1): 1-13.

Lau, Dora C. and Robert C. Liden. 2008. 'Antecedents of coworker trust: Leaders' blessings'. Journal of Applied Psychology 93(5): 1130-38.

Lewicki, R.J., D.J. McAllister and R.J. Bies. 1998. 'Trust and distrust: New relationships and realities'. Academy of Management Review 23(3): 438-58. 
Lewicki, Roy J., Edward C. Tomlinson and Nicole Gillespie. 2006. 'Models of interpersonal trust development: Theoretical approaches, empirical evidence, and future directions'. Journal of Management 32(6): 991-1022.

Lyon, F., G. Möllering and M.N.K. Saunders. 2015. 'Introduction. Researching trust: The ongoing challenge of matching objectives and methods'. In F. Lyon, G. Möllering and M.N.K. Saunders (eds) Handbook of Research Methods on Trust (2nd edn). Cheltenham, UK and Northampton, MA, USA: Edward Elgar Publishing.

Maguire, Steve, Nelson Philips and Cynthia Hardy. 2001. "When "silence = death", keep talking: Trust, control and the discursive construction of identity in the Canadian HIV/AIDS Treatment Domain'. Organization Studies 22(2): 285-310.

Mayer, Roger C. and James H. Davis. 1999. 'The effect of the performance appraisal system on trust for management: A field quasi-experiment'. Journal of Applied Psychology 84(1): 123-36.

McAllister, D.J. 1995. 'Affect- and cognition-based trust as a foundation for interpersonal cooperation in organizations'. Academy of Management Journal 38(1): 24-59.

Mohr, L.B. 1982. Explaining Organizational Behavior: The Limits and Possibilities of Theory and Research. San Francisco, CA: Jossey Bass.

Möllering, Guido. 2001. 'The nature of trust: From Georg Simmel to a theory of expectation, interpretation and suspension'. Sociology 35(2): 403-20.

Möllering, Guido. 2006. Trust: Reason, Routine, Reflexivity. Amsterdam: Elsevier.

Möllering, Guido. 2013. 'Process views of trusting and crises'. In Reinhard Bachmann and Akbar Zaheer (eds) Handbook of Advances in Trust Research. Cheltenham, UK and Northampton, MA, USA: Edward Elgar Publishing, pp. 285-305.

Nikolova, Natalia, Guido Möllering and Markus Reihlen. 2015. 'Trusting as a "leap of faith": Trust-building practices in client-consultant relationships'. Scandinavian Journal of Management 31(2): 232-45.

Sabel, Charles F. 1993. 'Studied trust: Building new forms of cooperation in a volatile economy'. Human Relations 46(9): 1133-70.

Saunders, Mark N.K., Denise Skinner, Graham Dietz, Nicole Gillespie and Roy J. Lewicki. 2010. Organizational Trust. A Cultural Perspective. Cambridge: Cambridge University Press.

Welch, Catherine and Eriikka Paavilainen-Mäntymäki. 2014. 'Putting process (back) in: Research on the internationalization process of the firm'. International Journal of Management Reviews 16: 2-23.

Whitehead, Alfred North. 1929. Process and Reality: An Essay in Cosmology. New York: Macmillan.

Wright, Alex and Ina Ehnert. 2010. 'Making sense of trust across cultural contexts'. In Mark N.K. Saunders, Denise Skinner, Graham Dietz, Nicole Gillespie and Roy J. Lewicki (eds) Organizational Trust: A Cultural Perspective. Cambridge University Press, pp. 107-26.

Zand, Dale E. (1972). 'Trust and managerial problem solving'. Administrative Science Quarterly 17(2): 229-39. 